\title{
FLORA DE GRÃO-MOGOL, MINAS GERAIS: MYRTACEAE ${ }^{1}$
}

\author{
MARIA LUCIA KAWASAKI \\ Instituto de Botânica, Caixa Postal 4005, 04301-002 - São Paulo, SP, Brasil \\ Endereço atual: Field Museum of Natural History, Roosevelt Road at Lake Shore Drive, \\ Chicago, Illinois 60605-2496, U.S.A.
}

BerG, O.K. 1857-59. Myrtaceae. In C.F.P. Martius (ed.) Flora brasiliensis. Frid. Fleischer. Leipzig, vol. 14, pars. 1, p. 1-655. KaWASAKI, M.L. 1989. Flora da Serra do Cipó, Minas Gerais: Myrtaceae. Bol. Bot. Unit. São Paulo 11: 121-170.

Kiaerskou, H. 1893. Enumeratio Myrtacearum brasiliensium. In J.E.B. Warming (ed.) Symbolae ad floram Brasiliae centralis cognoscendam. Vid. Mess. Nat. For. Kjøbenhavn. Copenhagen, vol. 39, p. 1-200.

LANDrum, L.R. \& KaWASAKI, M.L. 1997. The genera of Myrtaceae in Brazil: an illustrated synoptic treatment and identification keys. Brittonia 49: 508-536.

McVaugh, R. 1968. The genera of American Myrtaceae - an interim report. Taxon 17: 354-418.

Nic Lughadha, E. 1995. Myrtaceae. In B.L. Stannard (ed.) Flora of the Pico das Almas, Bahia, Brazil. Royal Botanic Gardens. Kew, p. 492-517.

1. Flores em panículas; embrião com radícula alongada e cotilédones desenvolvidos, foliáceos e muito dobrados (mircióide).

2. Ramos com disposição tipicamente bifurcada; cálice, no botão floral, completamente fechado, caliptriforme e circunciso, ou parcialmente fechado, 4-5-lobado, rompendo-se irregularmente na antese, decíduo no fruto.

3. Cálice completamente fechado, caliptriforme e circunciso na antese Calyptranthes brasiliensis 3'. Cálice parcialmente fechado, 4-5-lobado, rompendo-se em lobos irregulares na antese Marlierea

2'. Ramos não bifurcados; cálice, no botão floral, aberto, com 5 lobos distintos e regulares, persistentes no fruto.

4. Sacos polínicos das anteras dispostos em níveis diferentes; deiscência aparentemente sigmóide Gomidesia

4'. Sacos polínicos das anteras dispostos no mesmo nível; deiscência longitudinal Myrcia

1'. Flores solitárias, em dicásios, racemos, ou aparentemente fasciculadas ou aglomeradas por redução do eixo principal das inflorescências; embrião com radícula alongada ou espiralada e cotilédones muito pequenos, foliáceos (mirtóide) ou com radícula inconspícua e cotilédones desenvolvidos, carnosos (eugenióide).

5. Cálice, no botão floral, parcialmente ou completamente fechado, rompendo-se em lobos irregulares na antese Psidium guineense

5'. Cálice, no botão floral, aberto, com 4-5 lobos distintos e regulares.

6. Flores 5-meras Campomanesia

6'. Flores 4-meras.

7. Flores em dicásios; embrião mirtóide Blepharocalyx salicifolius

7'. Flores solitárias, em racemos, ou aparentemente fasciculadas ou aglomeradas; embrião eugenióide.

8. Flores aglomeradas; lobos do cálice e hipanto decíduos após a antese, deixando cicatriz circular no fruto Myrciaria gladuliflora

8'. Flores solitárias, em racemos, ou aparentemente aglomeradas ou fasciculadas; lobos do cálice persistentes no fruto Eugenia

\footnotetext{
' Trabalho realizado conforme o planejamento apresentado por Pirani el al. (2003). Bol. Bot. Univ. São Paulo 21(1): 1-24.
} 
Obs.: Gomidesia e Marlierea diferenciam-se de Myrcia essencialmente pela morfologia das anteras (Gomidesia) e do cálice (Marlierea). Estas características são reconhecidamente pouco consistentes e, com freqüência, as espécies destes dois gêneros sāo atribuídas ao gênero $M y r c i a$.

\section{Blepharocalyx O. Berg}

LANDRUM, L.R. 1986. Blepharocalyx. Fl. Neotrop. Monogr. 45: 115-130.

Árvores ou arbustos. Flores em dicásios; cálice aberto, com 4 lobos regulares e distintos, decíduos, deixando cicatriz quadrangular no fruto; ovário 2-locular, vários óvulos por lóculo. Sementes 1-várias; testa membranácea; embrião mirtóide.

\subsection{Blepharocalyx salicifolius (Kunth) O. Berg, Linnaea 27: 413. 1856.}

Arbusto a árvore 2-4 m alt.; pilosidade amarelada a esbranquiçada. Folhas estreitamente elípticas ou lanceoladas, cartáceas a coriáceas; lâmina 2-4 cm x 0,8-1,5 $\mathrm{cm}$, pubescente a glabra; pontuações salientes em ambas as faces; ápice obtuso, agudo a acuminado; base cuneada a obtusa; nervura central plana na face adaxial, saliente na abaxial; nervuras laterais numerosas, indistintas a pouco salientes em ambas as faces; pecíolo $2-5 \mathrm{~mm}$ compr. Dicásios axilares, 2-3 cm compr., pubescentes; botões 3-4 mm compr., pubescentes; lobos do cálice suborbiculares, ca. $2 \mathrm{~mm}$ compr, obtusos. Frutos globosos, ca. 5 mm diâm., glabros. (Fig. 1. M-N)

Cordeiro E Mello-Silva CFCR 10146 (ASU, NY, SP, SPF); Cordeiro et al. CFCR 9041 (ASU, NY, SP, SPF); Mello-Silva $\mathcal{E}$ Cordeiro CFCR 10106 (NY, SP, SPF); Silva et al. CFCR 13494 (ASU, NY, SP, SPF).

Amplamente distribuída nas Regiões Centro-Oeste, Sudeste e Sul do Brasil, Paraguai, Uruguai, Argentina, Bolívia, Equador e provavelmente Peru; apresenta morfologia foliar extremamente variável. Em Grão-Mogol, foi coletada em campo rupestre e carrascal, com flores em setembro e frutos em janeiro.

\section{Calyptranthes Sw.}

Árvores ou arbustos; ramos bifurcados. Flores em panículas; cálice completamente fechado no botão floral, caliptriforme e circunciso, deixando cicatriz circular no fruto; ovário 2-locular, 2 óvulos por lóculo. Sementes 1-2; testa membranácea; embrião mircióide.

\subsection{Calyptranthes brasiliensis Spreng., Syst. veg. 2: 499. 1825.}

Arbusto 0,5-1,5 m alt.; pilosidade avermelhada a ferrugínea. Folhas elípticas a estreitamente elípticas ou ovadas, coriáceas; lâmina 3,5-7,5 cm x 2-3 cm, glabra na face adaxial, pubescente a pubérula na face abaxial; pontuações impressas na face adaxial, salientes na abaxial; ápice agudo a arredondado; base obtusa; nervura central sulcada na face adaxial, saliente na abaxial; nervuras laterais indistintas na face adaxial, salientes na abaxial; pecíolo 2-3 mm compr. Panículas terminais, 4,5-
$10 \mathrm{~cm}$ compr., pubescentes; botões ca. $2 \mathrm{~mm}$ compr., pubescentes. Frutos globosos, ca. $5 \mathrm{~mm}$ diâm., pubescentes a pubérulos. (Fig. 1. B-D)

Mello-Silva $\mathcal{E}^{\circ}$ Cordeiro CFCR 10147 (SP, SPF); Sano et al. CFCR 12731 (K, NY, SPF); Silva et al. CFCR 13347 (NY, SPF).

Regiões Sudeste e Nordeste (Bahia). Em Grão-Mogol, foi coletada em cerrado e carrascal, com flores em dezembro e frutos em setembro.

\section{Campomanesia Ruiz \& Pav.}

Landrum, L.R. 1986. Campomanesia. Fl. Neotrop. Monogr. 45: 7-72.

Árvores ou arbustos. Flores geralmente solitárias; cálice aberto, com 5 lobos regulares e distintos, persistentes no fruto; ovário 4-18-locular, vários óvulos por lóculo. Sementes 1-várias; “testa” (parede locular) cartilaginosa, glandulosa; embrião mirtóide. 
Flora de Grão-Mogol, Minas Gerais: Myrtaceae
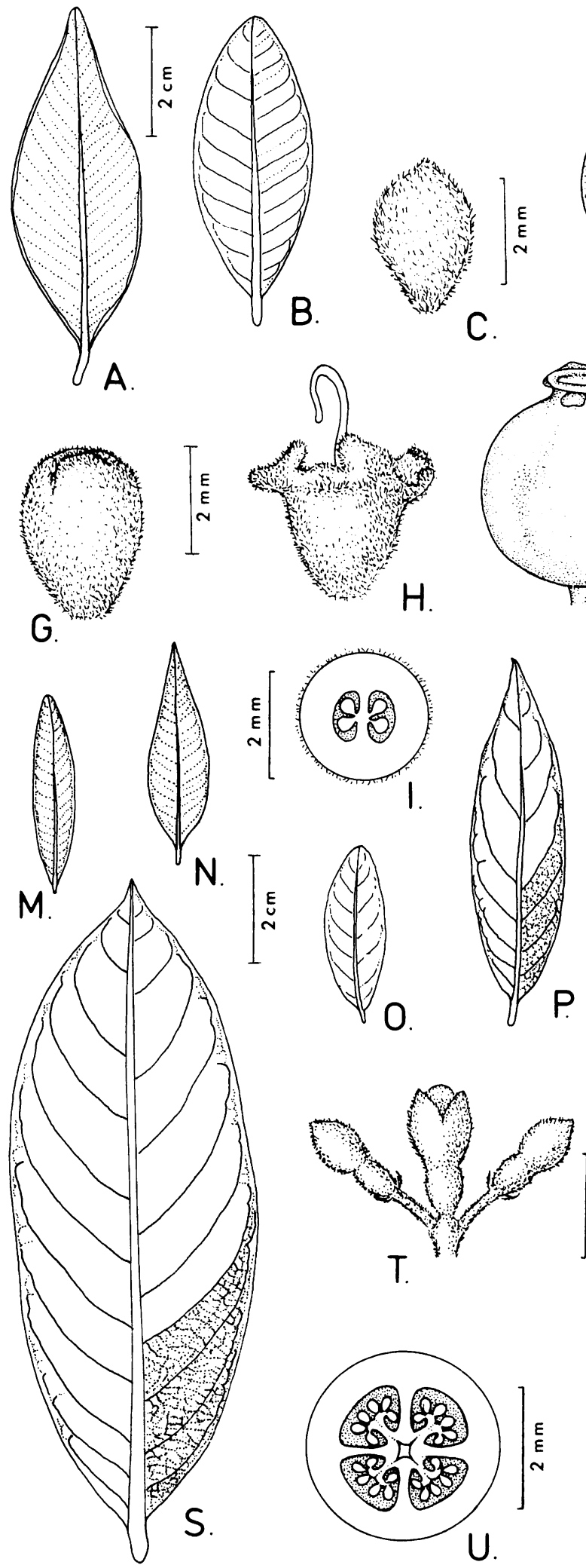

$\mathrm{J}$.
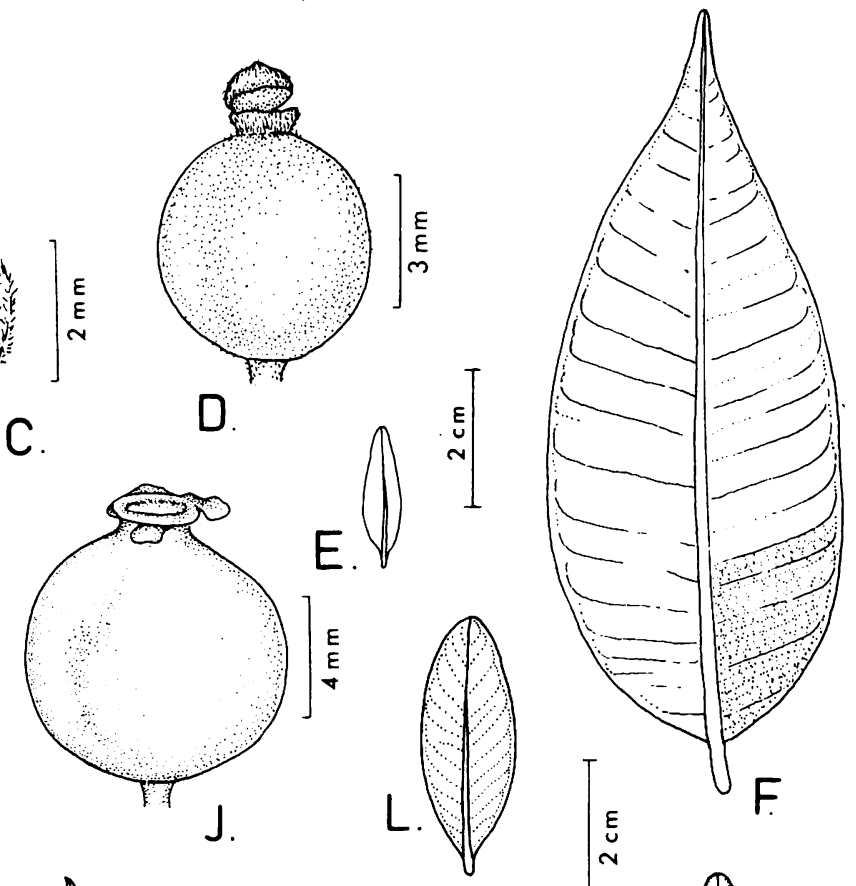

E.
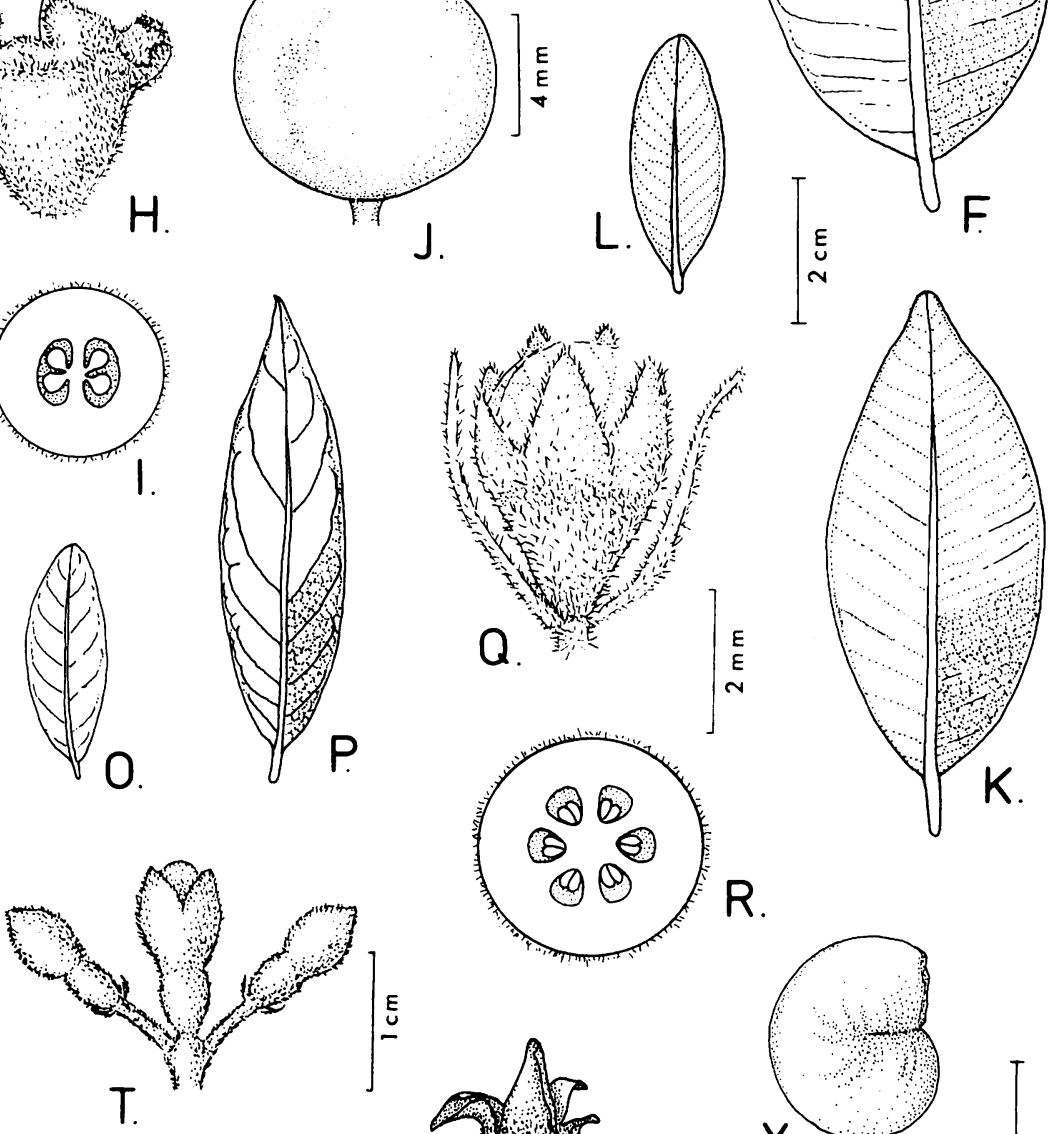

$\mathrm{R}$.
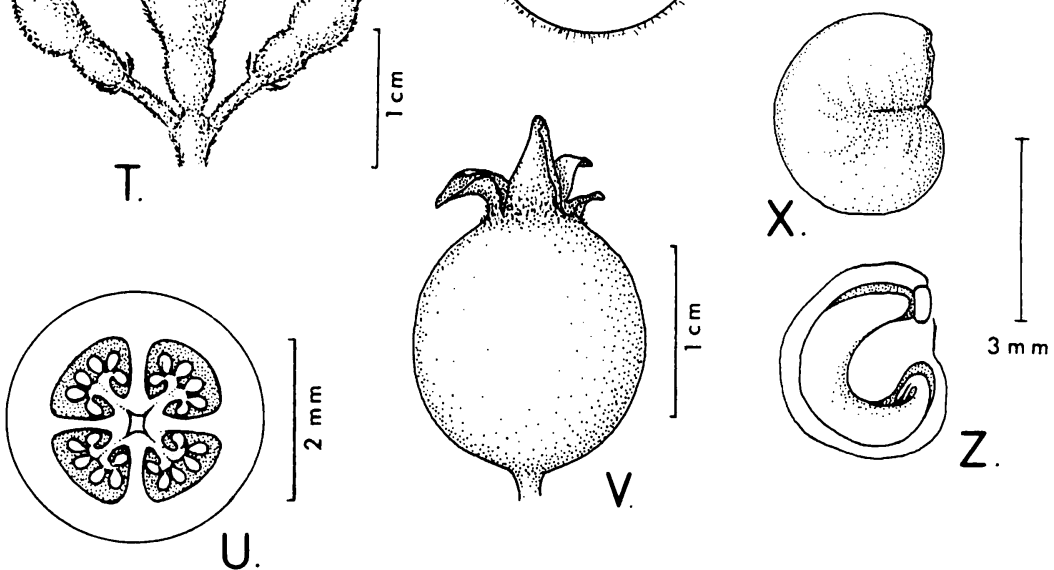

Fig. 1. MYRTACEAE. A. Myrciaria glanduliflora: folha. B-D. Calyptranthes brasiliensis: B. Folha; C. Botāo floral; D. Fruto. E. Marlierea angrustifolia: folha. F-J. M. clausseniana: F. Folha; G. Botão floral; H. Flor após antese; I. Ovário, corte transversal; J. Fruto. K. M. pilodes: folha. L. M. rubiginosa: folha. M-N. Blepharocalyx salicifolius: folhas. O. Campomanesia adamantium: folha. P-R. C. pubescens: P. Folha; Q. Botão floral; R. Ovário, corte transversal. S-Z. Psidium guineense: S. Fol ha; T. Inflorescência; U. Ovário, corte transversal; V. Fruto; X. Semente; Z. Embrião. 
1. Râmulos, folhas, pedúnculos e flores glabros ....

C. adamantium

1'. Râmulos, folhas, especialmente na face abaxial, pedúnculos e flores densamente pubescentes C. pubescens

3.1. Campomanesia adamantium (Cambess.) O. Berg, Linnaea 27: 434. 1856.

Arbusto ca. 0,6 m alt. Folhas (jovens) elípticas a estreitamente elípticas, ou oblanceoladas, membranáceas a cartáceas; lâmina 3-4,5 cm x 1-1,5 cm, glabra; pontuações salientes em ambas as faces; ápice agudo a obtuso; base obtusa a cuneada; nervura central sulcada na face adaxial, saliente na abaxial; nervuras laterais 5-9 pares, salientes em ambas as faces; pecíolo 1-5 mm compr. Peclúnculos axilares, 1-2,5 cm compr., glabros; botões 5-6 mm compr., glabros; lobos do cálice ovados, 2-3 mm compr., obtusos. (Fig. 1. O)

\section{Campos et al. CFCR 13485 (NY, SP, SPF).}

Regiões Centro-Oeste, Sudeste e Sul do Brasil, e Paraguai; em campos e cerrados. Em Grão-Mogol, foi coletada em cerrado, com flores em setembro.

3.2. Campomanesia pubescens (DC.) O. Berg, Linnaea 27: 429. 1856.

Arbusto 1-1,5 m alt.; pilosidade amarelada a esbran- quiçada. Folhas estreitamente elípticas ou lanceoladas, coriáceas; lâmina $4-7 \mathrm{~cm} \times 1-3 \mathrm{~cm}$, pubescente a glabra na face adaxial, densamente pubescente na abaxial; pontuações indistintas em ambas as faces ou salientes na face abaxial; ápice acuminado a obtuso; base obtusa a cuneada; nervura central sulcada na face adaxial, saliente na abaxial; nervuras laterais 6-8 pares, sulcadas na face adaxial, salientes na abaxial; pecíolo $2-5 \mathrm{~mm}$ compr. Pedúnculos axilares, 0,5-3,5 cm compr., pubescentes; botões ca. $5 \mathrm{~mm}$ compr., pubescentes; lobos do cálice lanceolados, 3-7 mm compr., agudos a obtusos. Frutos globosos, ca. $1 \mathrm{~cm}$ diâm., pubescentes. (Fig. 1. P$\mathrm{R})$

Esteves et al. CFCR 13271 (ASU, NY, SP, SPF); Harley et al. 25006 (SP, SPF); Mello-Silva et al. CFCR 10178 (NY, SP, SPF); Pirani et al. CFCR 13244 (NY, SPF).

Regiões Centro-Oeste, Nordeste, Sudeste e Sul do Brasil, e Paraguai; em campos e cerrados. Em GrãoMogol, foi coletada em campo rupestre, carrascal e cerrado, com flores em setembro e outubro, e frutos em setembro.

\section{Eugenia L.}

Árvores ou arbustos. Flores solitárias, em racemos, ou aparentemente fasciculadas ou aglomeradas por redução do eixo principal das inflorescências; cálice aberto, com 4 lobos regulares e distintos, persistentes no fruto; ovário 2 locular, vários óvulos por lóculo. Sementes 1-2; testa membranácea; cmbrião eugenióide.

1. Flores em racemos.

2. Folhas ovadas, glabras; racemos pubérulos com flores pediceladas E. neglecta

2'. Folhas elípticas a estreitamente elípticas, velutinas na face abaxial; racemos velutinos com flores subsésseis E. velutina

1'. Flores solitárias, aos pares nas axilas foliares, ou fasciculadas.

3. Bractéolas decíduas; lobos do cálice oblongos ou lanceolados, $49 \mathrm{~mm}$ compr., cobrindo as pétalas no botão floral.

4. Folhas coriáceas; nervuras laterais salientes na face adaxial, indistintas na abaxial; flores solitárias, pubescentes.

4'. Folhas cartáceas; nervuras laterais densamente reticuladas e salientes em ambas as faces; flores em fascículos, glabras E. dysenterica

3'. Bractéolas persistentes; lobos do cálice ovados a suborbiculares, 1-3 mm compr., não cobrindo as pétalas no botão floral.

5. Folhas ovadas a lanceoladas; base subcordada a cordada.

6. Folhas glabras; margens geralmente planas

E. bimarginata

$6^{\prime}$. Folhas ferrugíneo- a ocráceo-tomentosas na face abaxial; margens revolutas E. blanda

5 '. Folhas estreitamente elípticas a elípticas ou obovadas a oblanceoladas; base cuneada a obtusa.

7. Nervura central plana a saliente na face adaxial. E. hilariana

7'. Nervura central sulcada na face adaxial. 
8. Flores solitárias ou aos pares nas axilas foliares.

9. Folhas $3-8 \mathrm{~cm} \times 1-3 \mathrm{~cm}$; nervuras laterais salientes em ambas as faces; margens planas E. punicifolia

9'. Folhas 2-3,5 cm x 4-8 $\mathrm{mm}$; nervuras laterais indistintas em ambas as faces; margens revolutas

8'. Flores fasciculadas.

10. Folhas coriáceas, brilhantes; nervuras laterais 12-15 pares, salientes em ambas as faces

E. tapacumensis

10 '. Folhas cartáceas, opacas; nervuras laterais 6-8 pares, indistintas a pouco salientes em ambas as faces

E. sonderiana

\subsection{Eugenia bimarginata DC., Prodr. 3: 271. 1828.}

Subarbusto ca. $80 \mathrm{~cm}$ alt. Folhas ovadas a lanceoladas, coriáceas; lâmina 1-3 cm x 0,5-1 cm, glabra; pontuações indistintas na face adaxial, salientes na face abaxial; ápice agudo a obtuso; base subcordada a cordada; nervura central saliente em ambas as faces; nervuras laterais indistintas em ambas as faces; pecíolo 1-2 mm compr. Pedúnculos solitários ou aos pares, axilares, 2-3 mm compr., glabros; lobos do cálice ovados, ca. $1 \mathrm{~mm}$ compr., obtusos. Frutos elipsóides, ca. $1 \mathrm{~cm}$ compr., glabros. (Fig. 2. Q)

Campos et al. CFCR 13353 (NY, SPF).

Minas Gerais e Bahia. Em Grão-Mogol, foi coletada em cerrado, com frutos em setembro.

\subsection{Eugenia blanda Sobral, Bradea 6: 234. 1993.}

Arbusto ca. $1 \mathrm{~m}$ alt.; pilosidade ferrugínea a ocrácea. Folhas ovadas a lanceoladas, coriáceas, margens nitidamente revolutas; lâmina $5-7 \mathrm{~cm} \mathrm{x} \mathrm{2-2,5} \mathrm{cm,} \mathrm{glabra} \mathrm{na}$ face adaxial, tomentosa na abaxial; pontuações impressas na face adaxial, indistintas na abaxial; ápice agudo a obtuso; base cordada; nervura central saliente em ambas as faces; nervuras laterais ca. 10 pares, sulcadas na face adaxial, indistintas na abaxial; pecíolo até $1 \mathrm{~mm}$ compr. Flores lasciculadas, axilares; pedicelos até $5 \mathrm{~mm}$ compr., glabros; lobos do cálice ovados, 1-1,5 mm compr., agudos. Frutos imaturos elipsóides, ca. $5 \mathrm{~mm}$ compr., glabros. (Fig. 2. A)

Hatschbach et al. 54169 (holótipo MBM); Silvia et al. CFCR 13340 (SP, SPF).

Endêmica de Grão-Mogol, em campos rupestres e cerrados, com flores em junho e frutos em setembro.

\subsection{Eugenia dysenterica DC., Prodr. 3: 268. 1828.}

Arbusto ou árvore, 0,6-3 $\mathrm{m}$ alt. Folhas elípticas ou ovadas, cartáceas; lâmina 5,5-9 cın x 2,5-4,5 cm, glabra; pontuações salientes em ambas as faces; ápice agudo a obtuso; base obtusa a subcordada; nervura central sulcada na face adaxial, saliente na abaxial; nervuras laterais 7-10 pares, salientes em ambas as faces; pecíolo 3-5 mm compr. Flores fasciculadas, axilares, em râmulos foliares jovens; pedicelos 1-2 cm compr., glabros; bractéolas decíduas; botões 4-5 mm compr., glabros; lobos do cálice oblongos a lanceolados, ca. $4 \mathrm{~mm}$ compr., agudos. Frutos globosos, 2-3 cm diâm., glabros. (Fig. 2. B-C)

Pirani et al. CFCR 11353, CFCR 13483 (NY, SP, SPF).

Regiōes Nordeste, Centro-Oeste e Sudeste do Brasil, em cerrados e campos. Em Grão-Mogol, foi coletada em campos rupestres, com flores em setembro e frutos em novembro.

\subsection{Eugenia hilariana DC., Prodr. 3: 269. 1828.}

Arbusto 1-2,5 m alt. Folhas estreitamente elípticas, coriáceas; lâmina 4-8,5 cm x 1-2 cm, glabra; pontuações impressas na face adaxial, salientes na abaxial; ápice obtuso; base obtusa; nervura central plana a saliente na face adaxial, saliente na abaxial; nervuras laterais 10-12 pares, planas a salientes na face adaxial, salientes na abaxial; pecíolo 2-4 mm compr. Flores fasciculadas, axilares; pedicelos até $5 \mathrm{~mm}$ compr., glabros; botões ca. 3 mm compr., glabros; lobos do cálice ovados, ca. $1 \mathrm{~mm}$ compr., obtusos. (Fig. 2. E)

Hatschbach 41307 (MBM, SPF); Zappi et al. CFCR 12823 (SP, SPF).

Minas Gerais. Em Grão-Mogol, foi coletada em campo rupestre e em margens de riachos, com flores em setembro e novembro.

4.5. Eugenia laruotteana Cambess. in A. St.-Hil., Fl. Bras. merid. 2: 350.1833.

Arbusto a árvore 2-6 m alt.; pilosidade esbranquiçada. Folhas estreitamente elípticas a elípticas, quando jovens, 


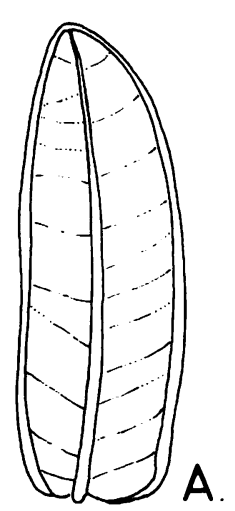

Kawasaki
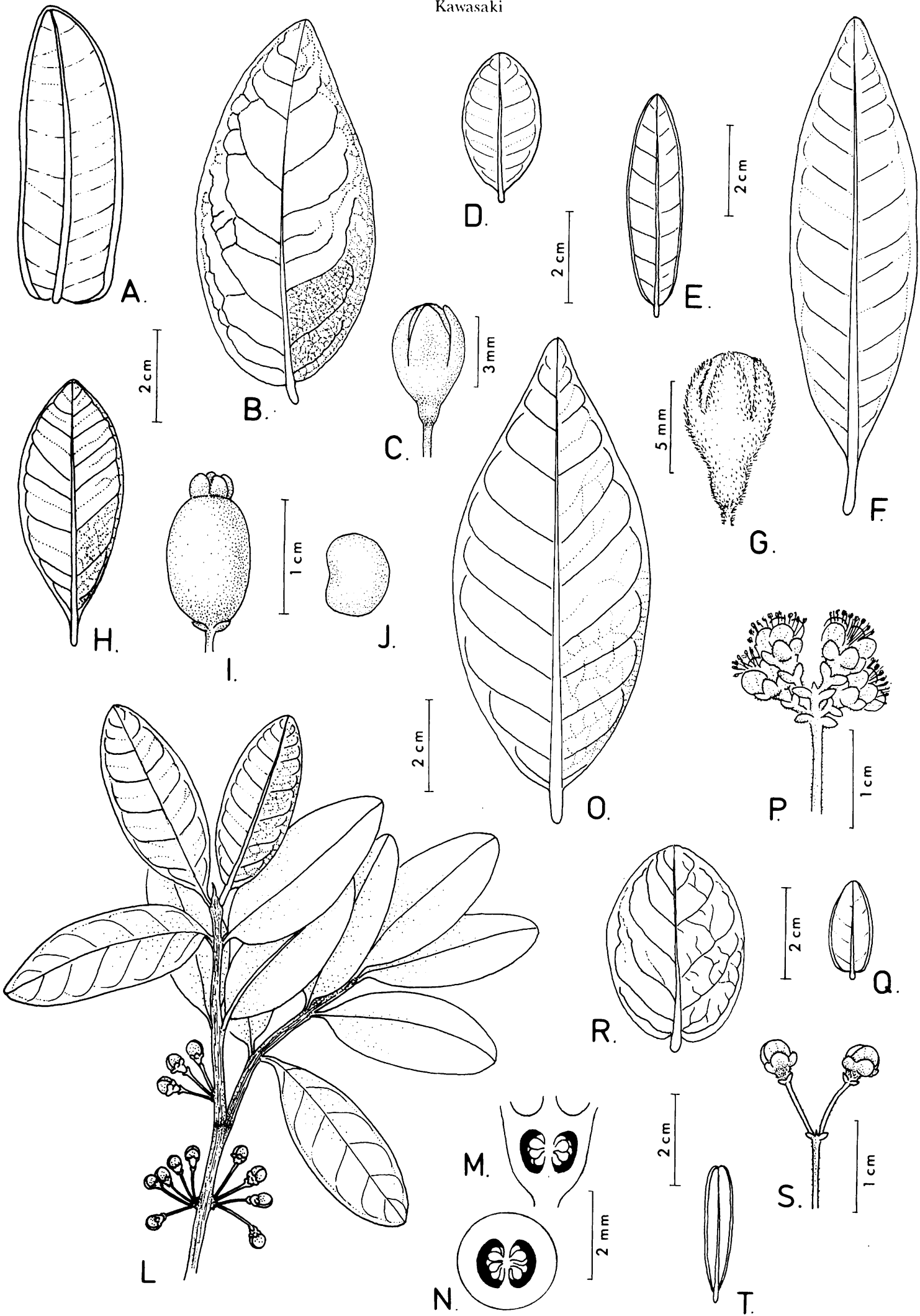

Fig. 2. MYRTACEAE. Eugenia. A. E. blanda: folha. B-C. E. dysenterica: B. Folha; C. Botão floral. D. E. somderiana: folha. E. E. hilariana: folha. F-G. E. laruotteana: F. Folha; G. Botão floral. H-J. E. punicifolia: H. Folha; I. Fruto; J. Embriāo. L-N. L. lapacumensis: L. Hábito; M. Ovário. corte longitudinal; N. Ovário, corte transversal. O-P. E. velutina: O. Folha; P. Inflorescência. Q. E. bimarginata: folha. R-S. E. neglecta: R. Folha; S. Inflorescência. T. Eugenia sp.: folha. 
membranáceas e pubescentes, posteriormente coriáceas e glabras; lâmina $5,5-10 \mathrm{~cm}$ x 2-4,5 cm; pontuações impressas ou indistintas na face adaxial, salientes na abaxial; ápice agudo; base cuneada a obtusa; nervura central sulcada na face adaxial, saliente na abaxial; nervuras laterais 6-12 pares, salientes na face adaxial, indistintas na abaxial; pecíolo 0,8-1 cm compr. Pedúnculos solitários, axilares, 1-2 cm compr., pubescentes; bractéolas decíduas; botões 0,8-1 cm compr., pubescentes a pubérulos; lobos do cálice lanceolados, 6-9 mm compr., agudos. (Fig. 2. F-G)

Mello-Silua et al. CFCR 10160 (SP, SPF); Pirani et al. CFCR 13475 (SP, SPF); Silva et al. CFCR 13380 (SP, SPF).

Minas Gerais. Em Grão-Mogol, foi coletada em cerrados, matas e campos rupestres, com flores em setembro.

4.6. Eugenia neglecta O. Berg, in Mart., Fl. bras. 14(1): 320. 1857.

Subarbusto 0,6-1 m alt. Folhas ovadas, coriáceas; lâmina 3,5-7 cm x 2-4,5 cm, glabra; pontuaçòes impressas na face adaxial, salientes na abaxial; ápice agudo a obtuso; base subcordada; nervura central sulcadla na face adaxial, saliente na abaxial; nervuras laterais $6-8$ pares, salientes em ambas as faces; pecíolo $1-2 \mathrm{~mm}$ compr. Racemos pouco desenvolvidos, 2-2,5 cm compr., axilares; pedicelos ca. $1 \mathrm{~cm}$ compr., pubérulos; botões até $5 \mathrm{~mm}$ compr., pubescentes a pubérulos; lobos do cálice ovados a suborbiculares, 3-4 mm compr., obtusos. Frutos subglobosos, 1,5-2 cm diâm., glabros. (Fig. 2. R-S)

Cordeiro et al. CFCR 987 (NY, SPF); Sano et al. CFCR 12548 (NY, SPF).

As duas coleções de Grāo-Mogol foram coletadas em cerrados e margens de rios, com flores (inflorescências muito jovens) em dezembro e frutos (soltos, sem eixos de inflorescências) em abril. Aparentemente, podem ser atribuídas a E. neglecta (Field Mus. neg. 19973), espécie pouco conhecida, coletada somente em Minas Gerais.

\subsection{Eugenia punicifolia (Kunth) DC., Prodr: 3: 267. 1828.}

Arbusto a arvoreta, 0,5-5 $\mathrm{m}$ alt. Folhas estreitamente elípticas a elípticas, ou obovadas a oblanceoladas, coriáceas; lâmina $3-8 \mathrm{~cm} \times 1-3 \mathrm{~cm}$, glabra na face adaxial, pubérula a glabra na abaxial; pontuações indistintas na face adaxial, salientes na abaxial; ápice agudo a obtuso; base cuneada; nervura central sulcada na face adaxial, saliente na abaxial; nervuras laterais 8-12 pares, salientes em ambas as faces; pecíolo 1-5 mm compr. Pedúnculos solitários ou aos pares, axilares, 5-15 mm compr., pubérulos; botōes 3-4 mm compr., pubérulos; lobos do cálice ovados, 2-3 mm compr., obtusos. Frutos elipsóides, até $1,5 \mathrm{~cm}$ compr., glabros. (Fig. 2. H-J)

Campos et al. CFCR 13459 (NY, SPF); Mamede et al. CFCR 3518 (ICN, MICH, SPF); Mello-Silva \& Cordeiro CFCR 10008 (NY, SPF); Mello-Silva Eे Pirani CFCR 10895 (SP, SPF); Mello-Silva et al. CFCR 9847 (ASU, SP, SPF); Oliveira et al. CFCR 12947 (SPF); Pirani et al. CFCR 12664 (ASU, NY, SPF); Zappi et al. CFCR 12833, CFCR 12978, CFCR 13163 (NY, SPF).

América do Sul, em campos e cerrados, com morfologia foliar extremamente variável. Em GrãoMogol, foi coletada em cerrado e carrascal, com flores em junho e dezembro, e com frutos de maio a setembro.

4.8. Eugenia sonderiana O. Berg in Mart., Fl. bras. 14(1): 270.1857.

Arbusto ca. 1,5 m alt. Folhas elípticas ou obovadas, cartáceas; lâmina 2-3,5 cm x 1-2 cm, glabra; pontuaçōes indistintas ou salientes na face adaxial, salientes na abaxial; ápice agudo a obtuso; base cuneada a obtusa; nervura central sulcada na face adaxial, saliente na abaxial; nervuras laterais 6-8 pares, indistintas a pouco salientes em ambas as faces; pecíolo 1-2 mm compr. Flores fasciculadas, axilares e terminais; pedicelos 3-5 mm compr. pubérulos: botòes ca. $2 \mathrm{~mm}$ compr., pubérulos; lobos do cálice suborbiculares, ca. $1 \mathrm{~mm}$ compr., obtusos. (Fig. 2. D)

\section{Assis et al. CFCR 11450 (NY, SP, SPF).}

Minas Gerais. Coletada em Grão-Mogol com folhas e flores muito jovens em novembro.

4.9. Eugenia tapacumensis O. Berg, Linnaea 27: 222. 1856.

Arbusto 0,5-1,5 m alt. Folhas estreitamente elípticas a elípticas, ou obovadas a oblanceoladas, coriáceas; lâmina 3,5-6,5 cm x 1,5-2,5 cm, glabra; pontuações salientes em ambas as faces; ápice obtuso; base cuneada a obtusa; nervura central sulcada na face adaxial, saliente na abaxial; nervuras laterais $12-15$ pares, salientes em ambas as faces; pecíolo 2-3 mm compr. Flores fasciculadas, axilares; pedicelos até $1 \mathrm{~cm}$ compr., glabros; botões 3-4 mm compr., glabros; lobos do cálice ovados a suborbiculares, 1-1,5 mm compr., obtusos. (Fig. 2. L-N)

Sano et al. CFCR 12360, CFCR 12557, CFCR 12626 (SP, SPF). 
Desde o norte da América do Sul até o Sudeste do Brasil. Em Grão-Mogol, foi coletada em cerrado e carrascal, com flores em dezembro.

4.10. Eugenia velutina O. Berg in Mart., Fl. bras. 14(1): 317. 1857.

Arbusto ca. $2 \mathrm{~m}$ alt.; pilosidade esbranquiçada. Folhas estreitamente elípticas a elípticas, coriáceas; lâmina 5,5$10 \mathrm{~cm} \times 2,5-5,5 \mathrm{~cm}$, pubérula a glabra na face adaxial, velutina na abaxial; pontuações indistintas na face adaxial, salientes na abaxial; ápice agudo a acuminado; base obtusa; nervura central plana a saliente na face adaxial, saliente na abaxial; nervuras laterais 7-9 pares, planas na face adaxial, salientes na abaxial; pecíolo 3-5 mm compr. Racemos 1,5-2 cm compr., axilares; pedicelos até $1 \mathrm{~mm}$ compr., velutinos; botões ca. $5 \mathrm{~mm}$ compr., velutinos; lobos do cálice ovados, $2-3 \mathrm{~mm}$ compr., obtusos. (Fig. 2. O-P)

\section{Zappi et al. CFCR 8484 (NY, SPF).}

O material corresponde bem à descrição e ilustração (folha) de E. velutina. No entanto, são desconhecidas coletas e informações recentes sobre esta espécie. $O$ úni- co material estudado de Grão-Mogol foi coletado em beira de mata de encosta, com flores em setembro.

\subsection{Eugenia sp.}

Subarbusto 0,2-1 $\mathrm{m}$ alt. Folhas oblanceoladas, coriáceas; lâmina 2-3,5 cm x 4-8 mm, glabra, margens nitidamente revolutas; pontuações impressas na face adaxial, salientes na abaxial; ápice obtuso, retuso; base cuneada; nervura central sulcada na face adaxial, saliente na abaxial; nervuras laterais indistintas em ambas as faces; pecíolo 2-3 mm compr. Pedúnculos solitários ou aos pares, axilares, 5-8 mm compr., pubérulos a glabros; botões ca. $3 \mathrm{~mm}$ compr., pubérulos a glabros; lobos do cálice ovados, ca. $2 \mathrm{~mm}$ compr., agudos a obtusos. Frutos globosos, 5-8 mm diâm., pubérulos a glabros. (Fig. 2. T)

Cordeiro et al. CFCR 11426 (SP, SPF); Kawasaki et al. CFCR 1016 (SP, SPF), CFCR 6498 (ICN, K, NY, SPF).

Provavelmente uma espécie ainda não descrita, caracterizada pelas flores solitárias e folhas oblanceoladas, com nervuras laterais indistintas e margens nitidamente revolutas. Foi coletada em campos rupestres, com flores em outubro e novembro, e frutos em novembro.

\section{Gomidesia O.Berg}

Legrand, C.D. 1958. Las espécies tropicales del género Gomidesia (Myrtaceae). Comun. Bot. Mus. Hist. Nat. Monteriideo $3(37): 1-30$.

Árvores ou arbustos. Flores em panículas; cálice aberto, com 5 lobos regulares e distintos, persistentes no fruto; ovário 2-locular, 2 óvulos por lóculo; sacos polínicos das anteras dispostos em níveis diferentes, deiscência aparentemente sigmóide. Sementes 1-2; testa membranácea; embrião mircióide.

1. Folhas glabras a pubérulas, $5,5-12 \mathrm{~cm} \times 3-5 \mathrm{~cm}$; botões florais ca. $2 \mathrm{~mm}$ compr. G. minutiflora

1'. Folhas pubescentes na face abaxial, 3,5-9 cm x 1,5-4 cm; botões florais 3-5 mm compr.

2. Botões florais ca. $3 \mathrm{~mm}$ compr; lobos do cálice obtusos G. pubescens

2'. Botões florais ca. $5 \mathrm{~mm}$ compr.; lobos do cálice agudos Gomidesia sp.

5.1. Gomidesia minutiflora Mattos \& D. Legrand, Loefgrenia 67: 15. 1975.

Árvore ca. $2 \mathrm{~m}$ alt.; pilosidade amarelada. Folhas elípticas a estreitamente elípticas, coriáceas; lâmina 5,5$12 \mathrm{~cm} \times 3-5 \mathrm{~cm}$, glabra; pontuações salientes em ambas as faces; ápice acuminado; base obtusa; nervura central sulcada na face adaxial, saliente na abaxial; nervuras laterais 15-20 pares, salientes em ambas as faces; pecíolo ca. $5 \mathrm{~mm}$ compr. Panículas axilares, 4-7 cm compr., seríceas; botões ca. $2 \mathrm{~mm}$ compr., seríceos; lobos do cálice suborbiculares, ca. $1 \mathrm{~mm}$ compr., obtusos. (Fig. 3. A)

Sano et al. CFCR 12376 (K, SP, SPF).
Minas Gerais e Bahia, em cerrados. Em Grão-Mogol, foi coletada em carrascal, com flores em dezembro.

5.2. Gomidesia pubescens (DC.) D. Legrand, Com. Bot. Mus. Hist. Nat. Montevideo 3(37): 20. 1958.

Arbusto ou árvore 2-6 m alt.; pilosidade amarelada. Folhas elípticas a estreitamente elípticas ou ovadas, coriáceas; lâmina 3,5-9 cm x 1,5-4 cm, glabra na face adaxial, pubescente na adaxial; pontuações indistintas ou impressas na face adaxial, salientes na abaxial; ápice agudo a obtuso; base obtusa; nervura central sulcada na face adaxial, saliente na abaxial; nervuras laterais 810 pares, indistintas a salientes na face adaxial, salientes 
na abaxial; pecíolo 2-3 mm compr. Panículas axilares ou terminais, 4-12 cm compr., pubescentes; botões ca. 3 $\mathrm{mm}$ compr., pubescentes; lobos do cálice suborbiculares, 1-2 mm compr., obtusos. Frutos globosos, ca. $1 \mathrm{~cm}$ diâm., pubescentes. (Fig. 3. B-C)

Campos et al. CFCR 13421 (K, NY, SPF); Cordeiro \& Mello-Silva CFCR 10054 (NY, SP, SPF); Hatschbach 41639 (MBM); Mello-Silva E Cordeiro CFCR 9997 (NY, SP, SPF), CFCR 10100 (K, NY, SPF); Mello-Silva et al. CFCR 8427 (NY, SPF), CFCR 11477 (NY, SP, SPF); Pirani et al. CFCR 13144 (SP, SPF); Rapini et al. 344 (SP, SPF); Sano et al. CFCR 12402 (NY, SP, SPF), CFCR 12415 (NY, SP, SPF).

Regiões Centro-Oeste, Sudeste e Sul do Brasil. Em Grão-Mogol, foi coletada em mata ciliar e carrascal, com flores em novembro e dezembro, e frutos de setembro a dezembro.

\subsection{Gomidesia sp.}

Arbusto ca. $2 \mathrm{~m}$ alt.; pilosidade ferrugínea a ocrácea.
Folhas elípticas a estreitamente elípticas ou ovadas, coriáceas; lâmina $4-8 \mathrm{~cm} \times 2-3,5 \mathrm{~cm}$, glabra na face adaxial, pubescente a tomentosa na abaxial; pontuações impressas na face adaxial, salientes na abaxial; ápice agudo a acuminado; base obtusa a cuneada; nervura central sulcada na face adaxial, saliente na abaxial; nervuras laterais 8-12 pares, salientes em ambas as faces; pecíolo 3$5 \mathrm{~mm}$ compr. Panículas axilares, $6-12 \mathrm{~cm}$ compr., tomentosas; botões ca. $5 \mathrm{~mm}$ compr., tomentosos; lobos do cálice triangulares, ca. 3 mm compr., agudos. (Fig. 3. D)

Kameyama et al. CFCR 9030 (K, NY, SP, SPF); Kawasaki et al. CFCR 6513A (K, NY, SPF); Sano et al. CFCR 12438 (K, NY, SPF).

Aparentemente uma espécie distinta, não reconhecida entre as espécies descritas de Gomidesia. Poderia representar extremos de variações de espécies pouco conhecidas do gênero ou talvez de Myrcia, apesar das anteras características de Gomidesia. Em Grão-Mogol, foi coletada em campos rupestres, com flores de novembro a janeiro.

\section{Marlierea Cambess.}

Legrand, C.D. 1962. Sinopsis de las espécies de Marlierea del Brasil (Myrtaceae). Comun. Bot. Mus. Hist. Nat. Monterideo 3(40): 1-39.

Árvores ou arbustos; ramos freqüentemente bifurcados. Flores em panículas; cálice parcialmente fechado, 4-5lobado, rompendo-se na antese em lobos irregulares, decíduos no fruto; ovário 2-locular, 2 óvulos por lóculo. Sementes 1-2; testa membranácea; embrião mircióide.

1. Folhas 0,3-1,5 cm larg.; ápice geralmente obtuso; pecíolo 1-3 mm compr.

2. Folhas $1-2 \mathrm{~cm} \times 3-7 \mathrm{~mm}$ M. angustifolia

2'. Folhas $3-4,5 \mathrm{~cm} \times 1-1,5 \mathrm{~cm}$ M. rubiginosa

1'. Folhas 2-6 cm larg.; ápice geralmente acuminado; pecíolo 0,5-1 cm compr.

3. Face abaxial das folhas geralmente pubescente, com pontuações indistintas; inflorescências terminais..... M. pilodes

3'. Face abaxial das folhas pubescentes a glabras, densamente pontuadas; inflorescências terminais e axilares M. clausseniana

6.1. Marlierea angustifolia (O. Berg) Mattos, Ci. \& Cult. 19: 333. 1967.

Arbusto ou árvore 1-2 m alt.; pilosidade ferrugínea. Folhas estreitamente elípticas, coriáceas; lâmina $1-2 \mathrm{~cm}$ x 3-7 $\mathrm{mm}$, glabra na face adaxial, pubescente na abaxial; pontuações indistintas ou impressas na face adaxial, salientes na abaxial; ápice geralmente obtuso; base cuneada; nervura central plana na face adaxial, saliente na abaxial; nervuras laterais indistintas em ambas as faces; pecíolo 1-2 mm compr. Panículas terminais, 1,5-3 cm compr., pubescentes; botões ca. $2 \mathrm{~mm}$ compr., pubes- centes; lobos do cálice ovados a suborbiculares, ca. 1 mm compr., obtusos. Frutos globosos, ca. $5 \mathrm{~mm}$ diâm., pubescentes a glabros. (Fig. 1. E)

Cordeiro et al. CFCR 791 (SP, SPF); Hatschbach 41595 (MBM, SPF); Kawasaki et al. 1019 (SP, SPF); Mello-Silva et al. CFCR 8544 (NY, SP, SPF), CFCR 11463 (SP, SPF); Simão-Bianchini et al. CFCR 13087 (K, NY, SPF).

Minas Gerais. Em Grão-Mogol, foi coletada em campos rupestres, com flores de outubro a abril e frutos de setembro a junho. 
6.2. Marlierea clausseniana (O. Berg) Kiaersk., Enum. Myrt. bras. 51. 1893.

Arbusto ou árvore 1,5-5 m alt.; pilosidade avermelhada. Folhas elípticas a estreitamente elípticas, coriáceas; lâmina $5-13 \mathrm{~cm} \times 2-6 \mathrm{~cm}$, glabra na face adaxial, pubescente a glabra na abaxial; pontuações indistintas ou impressas na face adaxial, salientes na abaxial; ápice acuminado; base obtusa a cuneada; nervura central sulcada na face adaxial, saliente na abaxial; nervuras laterais numerosas, indistintas na face adaxial, salientes na abaxial; pecíolo 0,5-1 cm compr. Panículas axilares ou terminais, 3-12 cm compr., pubescentes; botões 2-3 $\mathrm{mm}$ compr., pubescentes; lobos do cálice suborbiculares, ca. $1 \mathrm{~mm}$ compr., obtusos. Frutos globosos, ca. $7 \mathrm{~mm}$ diâm., pubescentes a pubérulos. (Fig. 1. F-J)

Campos et al. CFCR 13321 (NY, SP, SPF); Cavalcanti et al. CFCR 8428 (SP, SPF); Cordeiro E Mello-Silva CFCR 10107 (NY, SP, SPF); Kawasaki et al. CFCR 8298 (SP, SPF); Mello-Silva et al. CFCR 11447 (SP, SPF); Pirani et al. CFCR 13269, CFCR 13425 (SP, SPF); Sano et al. CFCR 12571 (NY, SP, SPF), CFCR 12638 (K, NY, SPF).

Bahia, Minas Gerais e Rio de Janeiro. Em Grão-Mogol, foi coletada em cerrado, carrascal e campo rupestre, com flores em setembro e frutos'em novembro e dezembro.

6.3. Marlierea pilodes (Kiaersk.) M.L. Kawas., Bol. Bot. Univ. São Paulo 11: 126. 1989.

Árvore ca. $3 \mathrm{~m}$ alt.; pilosidade avermelhada a ocrácea. Folhas elípticas a estreitamente elípticas, coriáceas; lâmina $6-9 \mathrm{~cm} \times 2,5-3,5 \mathrm{~cm}$, glabra na face adaxial, pubescente a pubérula na abaxial; pontuações impressas na face adaxial, indistintas na abaxial; ápice agudo a acuminado; base obtusa a cuneada; nervura central sul- cada na face adaxial, saliente na abaxial; nervuras laterais numerosas, indistintas na face adaxial, salientes na abaxial; pecíolo 6-8 mm compr. Panículas terminais, 2,5$5 \mathrm{~cm}$ compr., pubescentes; botões $3-4 \mathrm{~mm}$ compr., pubescentes; lobos do cálice ovados, 1-2 mm compr., obtusos. Frutos imaturos globosos, ca. $5 \mathrm{~mm}$ diâm., pubescentes. (Fig. 1. K)

Mello-Silva et al. CFCR 11536 (SPF); Sano et al. CFCR 12714 (SPF).

Bahia e Minas Gerais. Em Grão-Mogol, foi coletada em matas, com flores em novembro e frutos em dezembro.

6.4. Marlierea rubiginosa (Cambess.) D. Legrand, Com. Bot. Mus. Hist. Nat. Montevideo 3: 32. 1962.

Arbusto ou árvore 1-2,5 m alt.; pilosidade avermelhada a ferrugínea. Folhas estreitamente elípticas, coriáceas; lâmina $3-4,5 \mathrm{~cm} \times 1-1,5 \mathrm{~cm}$, glabra na face adaxial, pubescente a pubérula na adaxial; pontuações impressas na face adaxial, salientes na abaxial; ápice geralmente obtuso; base obtusa a cuneada; nervura central plana a sulcada na face adaxial, saliente na abaxial; nervuras laterais indistintas em ambas as faces; pecíolo 2-3 mm compr. Panículas terminais, 3-5 cm compr., pubescentes; lobos do cálice suborbiculares, ca. $1 \mathrm{~mm}$ compr., obtusos. Frutos globosos, ca. 5 mm diâm., pubescentes a pubérulos. (Fig. 1. L)

Cordeiro et al. CFCR 9007 (SP, SPF); Kameyama et al. CFCR 9010 (SP, SPF); Kawasaki et al. CFCR 1018 (SP, SPF); Sano et al. CFCR 12469 (K, NY, SPF), CFCR 12564 (SP, $\mathrm{SPF})$.

Minas Gerais. Em Grão-Mogol, foi coletada em campos rupestres, com frutos de outubro a janeiro.

\section{Myrcia DC. ex Guill.}

Árvores ou arbustos. Flores em panículas; cálice aberto, com 5 lobos regulares e distintos, persistentes no fruto; ovário geralmente 2-3-locular, 2 óvulos por lóculo. Sementes 1-2; testa membranácea; embrião mircióide.

1. Folhas cordadas.

2. Pilosidade ocrácea a amarelada; ápice obtuso; glândulas salientes e visíveis em ambas as faces..... M. reticulosa

2'. Pilosidade esbranquiçada ou planta glabra; ápice agudo a acuminado; glândulas salientes e visiveis somente na face abaxial M. rhodeosepala

1'. Folhas cuneadas a obtusas na base (ocasionalmente subcordadas em M. tomentosa)

3. Nervura central plana a saliente na face adaxial.

4. Planta pubérula a glabra; folhas $4-8 \mathrm{~mm}$ larg. M. torta

4'. Râmulos, folhas jovens e inflorescências pubescentes a tomentosas; folhas $1-5,5 \mathrm{~cm}$ larg. 
5. Pilosidade amarelada; folhas cartáceas, pubescentes a tomentosas em ambas as faces: panículas com flores sésseis

5'. Pilosidade avermelhada; folhas coriáceas, geralmente pubérulas a glabras; panículas com flores pediceladas

3'. Nervura central sulcada na face adaxial.

6. Ápice geralmente obtuso.

7. Face adaxial das folhas com nervuras laterais e glândulas salientes; nervuras densamente reticuladas M. venulosa

7'. Face adaxial das folhas com nervuras laterais e glândulas impressas; nervuras inconspícuas.....

M. arborescens

6'. Ápice geralmente acuminado a rostrado.

8. Folhas $2-3,5 \mathrm{~cm} \times 4-9 \mathrm{~mm}$; ápice geralmente rostrado

M. rostrata

8'. Folhas 5-14 cm x 1,5-5,5 cm; ápice geralmente acuminado.

9. Pilosidade avermelhada; nervuras laterais 10-12 pares, indistintas a pouco salientes em ambas as faces

9'. Pilosidade amarelada; nervuras laterais 15-25 pares, salientes em ambas as faces M. fallax

7.1. Myrcia arborescens O. Berg in Mart., Fl. bras. 14(1): 200. 1857.

Árvore ca. $5 \mathrm{~m}$ alt.; pilosidade amarelada. Folhas elípticas ou ovadas, coriáceas; lâmina $2-3,5 \mathrm{~cm} \times 1-2 \mathrm{~cm}$, glabra na face adaxial, tomentosa a pubérula na abaxial; pontuações impressas na face adaxial, indistintas ou salientes na abaxial; ápice geralmente obtuso; base obtusa; nervura central sulcada na face adaxial, saliente na abaxial; nervuras laterais 10-12 pares, indistintas a pouco salientes em ambas as faces; pecíolo 1-3 mm compr. Panículas axilares ou terminais, muito jovens, até $3 \mathrm{~cm}$ compr., tomentosas a pubescentes; botões ca. $2 \mathrm{~mm}$ compr., pubescentes; lobos do cálice ovados a suborbiculares, ca. $1 \mathrm{~mm}$ compr., obtusos. (Fig. 3. E)

Cavalcanti et al. CFCR 10159 (SP, SPF).

Regiões Sudeste e Sul do Brasil. Em Grão-Mogol, foi coletada em matas, com flores em setembro.

\subsection{Myrcia detergens Miq., Linnaea 22: 795. 1849.}

Arbusto ca. $2 \mathrm{~m}$ alt.; pilosidade avermelhada. Folhas elípticas a estreitamente elípticas, coriáceas; lâmina 5-8 $\mathrm{cm} \times 1,5-2,5 \mathrm{~cm}$, pubérula na face adaxial, pubescente a pubérula na abaxial; pontuaçóes salientes em ambas as faces; ápice agudo a acuminado; base cuneada; nervura central sulcada na face adaxial, saliente na abaxial; nervuras laterais $10-12$ pares, indistintas a pouco salientes em ambas as faces; pecíolo 5-8 $\mathrm{mm}$ compr. Panículas axilares ou terminais, $5-8 \mathrm{~cm}$ compr., pubescentes; botòes ca. $2 \mathrm{~mm}$ compr., pubescentes; lobos do cálice triangulares, ca. $1 \mathrm{~mm}$ compr., agudos. (Fig. 3. F)

Sano et al. CFCR 12717 (K. NY, SPF).
Minas Gerais e Bahia. Em Grão-Mogol, foi coletada em cerrado, com flores em dezembro.

7.3. Myrcia fallax (Rich.) DC., Prodr. 3: 244. 1828.

Arbusto ou árvore 4-5 m alt.; pilosidade amarelada. Folhas elípticas a estreitamente elípticas ou lanceoladas, coriáceas; lâmina $5-14 \mathrm{~cm} \times 2-5,5 \mathrm{~cm}$, glabra na face adaxial, pubescente a pubérula na abaxial; pontuações indistintas ou salientes na face adaxial, salientes na abaxial; ápice acuminado; base cuneada; nervura central sulcada na face adaxial, saliente na abaxial; nervuras laterais 1525 pares, salientes em ambas as faces; pecíolo 5-7 $\mathrm{mm}$ compr. Panículas axilares ou terminais, 5-8 cm compr., pubescentes a pubérulas; lobos do cálice ovados, ca. 1-2 mm compr., obtusos. Frutos elipsóides, ca. $1 \mathrm{~cm}$ compr., pubescentes a pubérulos. (Fig. 3. G)

Assis et al. CFCR 11436 (SP, SPF); Mello-Silva et al. CFCR 8840 (SP, SPF).

Desde a América Central até o Sudeste do Brasil, sendo extremamente variável. Pertence a um complexo de espécies de difícil delimitação, provavelmente incluindo Myrcia guajarifolia O.Berg. Em Grão-Mogol, foi coletada em matas ciliares e em cerrados, com frutos em novembro e janeiro.

7.4. Myrcia guianensis (Aubl.) DC., Prodr. 3: 245. 1828.

Arbusto 1-2,5 $\mathrm{m}$ alt.; pilosidade avermelhada. Folhas elípticas a estreitamente elípticas, ou obovadas a oblanceoladas, coriáceas; lâmina $2,5-6 \mathrm{~cm}$ x $1-3 \mathrm{~cm}$, glabra na face adaxial, pubescente a glabra na face abaxial; pontuações impressas ou salientes na face adaxial, salientes na abaxial; ápice agudo a obtuso, retuso; base 

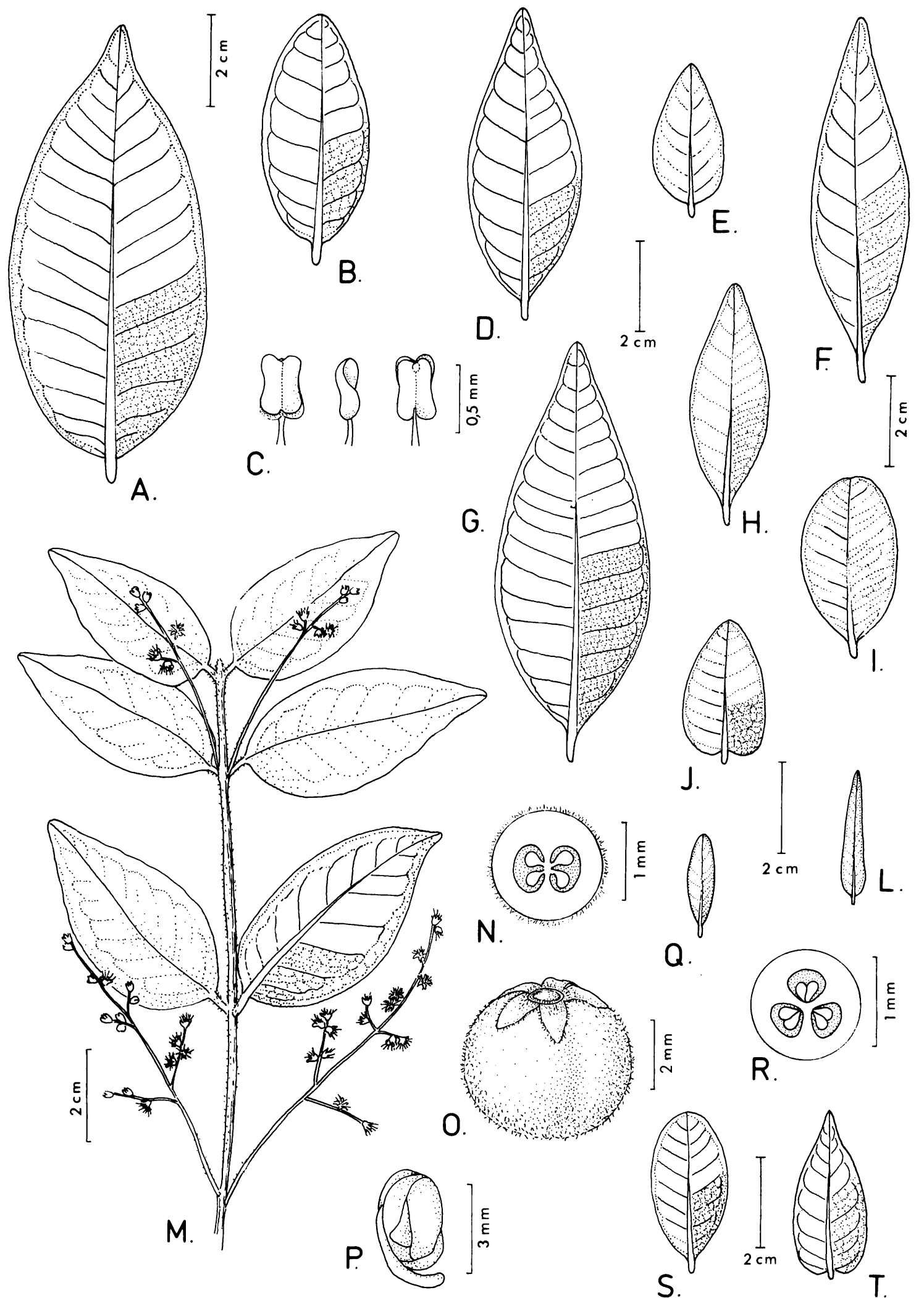

c. 
obtusa a cuneada; nervura central saliente em ambas as faces; nervuras laterais 10-15 pares, indistintas a salientes na face adaxial, salientes na abaxial; pecíolo $2-5 \mathrm{~mm}$ compr. Panículas axilares ou terminais, 3-7 cm compr., pubescentes a pubérulas; botões ca. $2 \mathrm{~mm}$ compr., pubescentes a pubérulos; lobos do cálice triangulares, ca. 1 mm compr., agudos a obtusos. Frutos imaturos subglobosos, ca. $5 \mathrm{~mm}$ diâm., pubérulos a glabros. (Fig. 3. H-I)

Cordeiro et al. CFCR 11414 (SP, SPF); Kameyama et al. CFCR 8884 (SP, SPF); Sano et al. CFCR 12742 (NY, SP, SPF); Silva et al. CFCR 13323 (SP, SPF).

Desde o norte da América do Sul até o Sudeste do Brasil, com morfologia foliar muito variável e formas com pilosidade mais densa (CFCR 13323). Em conseqüência desta variabilidade, inúmeras espécies atribuíveis ao complexo de $M$. guianensis foram descritas, provavelmente incluindo M. rufipes DC. Em Gräo-Mogol. foi coletada em cerrado, campo rupestre e mata ciliar, com flores de setembro a novembro e frutos de janeiro a dezembro.

\subsection{Myrcia reticulosa Miq., Linnaea 22: 794. 1849.}

Arbusto 1-1,5 m alt.; pilosidade ocrácea a amarelada. Folhas ovadas, coriáceas; lâmina $1,5-4 \mathrm{~cm} \times 1-2,5 \mathrm{~cm}$, glabra na face adaxial, pubescente a glabra na abaxial; pontuações salientes em ambas as faces; ápice obtuso; base cordada; nervura central plana na face adaxial, saliente na abaxial; nervuras laterais 7-10 pares, salientes em ambas as faces; pecíolo 1-3 mm compr. Panículas axilares ou terminais, 3-5 cm compr., pubescentes a pubérulas; botões 2-3 mm compr., glabros; lobos do cálice suborbiculares, ca. $1 \mathrm{~mm}$ compr., obtusos. (Fig. 3. J)

Hatschbach 41641 (MBM, SPF), 41597 (MBM); Kawasaki et al. CFCR 1014 (SP, SPF).

Minas Gerais e Bahia. Em Grão-Mogol, foi coletada em campos rupestres, com flores em outubro.

7.6. Myrcia rhodeosepala Kiaersk., Enum. Myrt. bras. 75. 1893.

Arbusto ca. $1 \mathrm{~m}$ alt. Folhas geralmente ovadas, coriáceas; lâmina 3-6,5 cm x 1,5-4 cm, pubérula a glabra em ambas as faces; pontuações indistintas na face adaxial, salientes na face abaxial; ápice agudo a acuminado; base cordada; nervura central saliente em ambas as faces; nervuras laterais $8-10$ pares, salientes em ambas as faces; pecíolo até $2 \mathrm{~mm}$ compr. Panículas axilares, 2,5-6 cm compr., glabras; botões 2-3 mm compr., glabros; lobos do cálice ovados, ca. $1 \mathrm{~mm}$ compr., obtusos. (Fig. 3. T)
Esteves et al. CFCR 13299 (NY, SPF).

Sudeste do Brasil. Em Grão-Mogol, foi coletada em cerrado, com flores em setembro.

\subsection{Myrcia rostrata DC., Prodr. 3: 255. 1828.}

Árvore 2-5 m alt.; pilosidade serícea. Folhas lanceoladas, cartáceas; lâmina 2-3,5 cm x 4-9 $\mathrm{mm}$, glabra na face adaxial, serícea na abaxial; pontuações impressas na face adaxial, indistintas na abaxial; ápice acuminado a rostrado; base cuneada a obtusa; nervura central sulcada na face adaxial, saliente na abaxial; nervuras laterais numerosas, indistintas em ambas as faces; pecíolo 2-3 $\mathrm{mm}$ compr. Panículas axilares ou terminais, $3-6 \mathrm{~cm}$ compr., seríceas; botões ca. $2 \mathrm{~mm}$ compr., seríceos; lobos do cálice ovados, ca. $1 \mathrm{~mm}$ compr., agudos. Frutos elipsóides, ca. $8 \mathrm{~mm}$ compr., pubérulos. (Fig. 3. L)

Kawasaki et al. CFCR 1013 (SP, SPF); Pirani et al. CFCR 13338 (SP, SPF); Sano et al. CFCR 12594 (NY, SP, SPF).

Desde o Nordeste até a região Sul do Brasil; extremamente variável, é incluída num complexo de espécies ainda pouco conhecido e com delimitação imprecisa. Em Grão-Mogol, foi coletada em cerrados, com flores de setembro a dezembro e frutos em dezembro.

7.8. Myrcia tomentosa (Aubl.) DC., Prodr. 3: 245. 1828.

Arbusto ou árvore 2-2,5 m alt.; pilosidade amarelada. Folhas elípticas a estreitamente elípticas ou obovadas a oblanceoladas, cartáceas; lâmina $5,5-11,5 \mathrm{~cm} \times 2-5,5 \mathrm{~cm}$, pubérula na face adaxial, tomentosa a pubescente na abaxial; pontuações indistintas ou salientes na face adaxial, salientes na face abaxial; ápice agudo a acuminado; base cuneada a subcordada; nervura central plana a saliente em ambas as faces; nervuras laterais 6-10 pares, salientes em ambas as faces; pecíolo 0,5-1 cm compr. Panículas axilares, 3-12 cm compr., tomentosas; botōes 3-4 mm compr., tomentosos; lobos do cálice ovados, ca. $1 \mathrm{~mm}$ compr., agudos. Frutos globosos, ca. $5 \mathrm{~mm}$ diâm., pubescentes. (Fig. 3. M-P)

Esteves et al. CFCR 13324, CFCR 13337 (NY, SP, SPF); Mello-Silva E Cordeiro CFCR 10085, CFCR 10137 (SP, SPF); Mello-Silva et al. CFCR 11452 (SP, SPF); Pirani et al. CFCR 11466 (SP, SPF), CFCR 11616 (NY, SP, SPF); Sano et al. CFCR 12494 (NY, SP, SPF).

Desde a América Central até o Sul do Brasil. Em GrãoMogol, foi coletada com flores de setembro a dezembro, e com frutos a partir de novembro. 
7.9. Myrcia torta DC., Prodr. 3: 250. 1828.

Arbusto 1,5-2 m alt. Folhas elípticas a estreitamente elípticas ou oblanceoladas, coriáceas; lâmina $1,5-2,5 \mathrm{~cm}$ $\mathrm{x}$ 4-8 mm, glabra em ambas as faces; pontuações impressas na face adaxial, salientes na abaxial; ápice obtuso; base cuneada; nervura central saliente em ambas as faces; nervuras laterais numerosas, salientes em ambas as faces; pecíolo 1-3 mm compr. Panículas axilares ou terminais, 2,5-6 cm compr., pubérulas a glabras; botões ca. $2 \mathrm{~mm}$ compr., glabros; lobos do cálice ovados a suborbiculares, ca. $1 \mathrm{~mm}$ compr., agudos a obtusos. Frutos globosos, ca. $5 \mathrm{~mm}$ diâm., glabros. (Fig. 3. Q-R)

Campos et al. CFCR 13266 (SPF); Cordeiro E Mello-Silva CFCR 10127 (NY, SP, SPF); Sano et al. CFCR 12663, CFCR 12674 (NY, SP, SPF).

Minas Gerais e Bahia. Em Grão-Mogol, foi coletada em campo rupestre e cerrado, com flores de setembro a dezembro e frutos em dezembro.

\subsection{Myrcia venulosa DC., Prodr. 3: 250. 1828.}

Arbusto 1-1,5 m alt.; pilosidade ferrugínea a amarelada. Folhas elípticas ou obovadas, coriáceas; lâmina $2-3,5 \mathrm{~cm} \times 1-1,5 \mathrm{~cm}$, glabra na face adaxial, pubescente a tomentosa na abaxial; pontuações salientes na face adaxial, salientes ou indistintas na abaxial; ápice obtuso; base cuneada a obtusa; nervura central sulcada na face adaxial, saliente na abaxial; nervuras laterais 10-12 pares, salientes em ambas as faces; pecíolo 1-3 mm compr. Panículas axilares ou terminais, $3-5 \mathrm{~cm}$ compr., pubescentes; botões ca. $3 \mathrm{~mm}$ compr., pubescentes; lobos do cálice ovados a suborbiculares, ca. $1 \mathrm{~mm}$ compr., agudos a obtusos. (Fig. 3. S)

Sano et al. CFCR 12464 (K. NY, SPF).

Regiōes Centro-Oeste, Sudeste e Sul do Brasil. Em Grão-Mogol, foi coletada em campo rupestre, com flores em dezembro.

\section{Myrciaria O.Berg}

Árvores ou arbustos. Flores aglomeradas nas axilas foliares. Cálice aberto, com 4 lobos regulares e distintos; hipanto circunciso e decíduo com o cálice após a antese, deixando cicatriz circular no fruto. Ovário 2-locular, 2 óvulos por lóculo. Sementes 1-2; testa membranácea; embrião eugenióide.

8.1. Myrciaria glanduliflora (Kiaersk.) Mattos \& D. Legrand, Loefgrenia 67: 6. 1975.

Arbusto 0,5-2 $\mathrm{m}$ alt. Folhas elípticas a estreitamente elípticas, coriáceas; lâmina 2,5-6,5 cm x 1-3 cm, glabra; pontuações impressas ou indistintas na face adaxial, salientes na abaxial; ápice agudo a acuminado; base obtusa a cuneada; nervura central plana a sulcada na face adaxial, saliente na abaxial; nervuras laterais indistintas em ambas as faces; margens revolutas; pecíolo $3-5 \mathrm{~mm}$ compr. Flores aglomeradas, axilares; bractéolas ca. $1 \mathrm{~mm}$ compr., ovadas, unidas na base; botões ca. 2 mm compr., densamente glandular-pontuados, glabros; lobos do cáli- ce suborbiculares, ca. $1 \mathrm{~mm}$ compr., obtusos. Frutos globosos, ca. 5 mm diâm., glabros. (Fig. 1. A)

Freire-Fierro et al. CFCR 12566 (NY, SP, SPF); Kameyama et al. CFCR 8846 (NY, SP, SPF); Mello-Silva Eं Cordeiro CFCR 10083 (NY, SP, SPF); Pirani et al. CFCR 8886 (NY, SP, SPF), CFCR 11442 (ASU, NY, SP, SPF); Simonis E Cordeiro CFCR 4151 (SPF); Zappi et al. CFCR 12971 (K, NY, SPF).

Minas Gerais, em matas. Em Grão-Mogol, foi coletada em carrascal e mata ciliar, com flores de setembro a junho e frutos em novembro.

\section{Psidium L.}

Árvores ou arbustos. Flores geralmente solitárias ou em dicásios; cálice completamente ou parcialmente fechado, rompendo-se na antese em lobos irregulares, decíduos no fruto; ovário geralmente 3-4-locular, vários óvulos por lóculo; placentação bilamelada. Sementes várias; testa óssea; embrião mirtóide.

\subsection{Psidium guineense Sw., Prodr. 77. 1788.}

Arbusto 1-1,5 m alt.; pilosidade ocrácea a amarelada. Folhas elípticas a estreitamente elípticas, coriáceas; lâ- mina 7-11 cm x 3,5-6 cm, glabra na face adaxial, pubescente na abaxial; pontuações salientes em ambas as faces; ápice agudo a obtuso; base obtusa a cuneada; nervura central sulcadia na face adaxial, saliente na face abaxial; 
nervuras laterais 5-10 pares, salientes em ambas as faces; pecíolo 0,5-1 cm compr. Dicásios axilares, até $4 \mathrm{~cm}$ compr., ou pedúnculos solitários, $1-2 \mathrm{~cm}$ compr., pubescentes; botões 1-1,3 cm compr., pubescentes. Frutos imaturos globosos, ca. 1,5 cm diâm., pubérulos. (Fig. 1. S-Z)

Assis et al. CFCR 11441 (ASU, NY, SP, SPF); Hatschbach
41622 (MBM, SPF); Kawasaki et al. 1017 (SP, SPF); Pirani et al. CFCR 12558 (NY, SP, SPF), CFCR 12602 (ASU, NY, $\mathrm{SP}, \mathrm{SPF})$.

América Central e América do Sul. Em Grão-Mogol, foi coletada em campos rupestres e cerrados, com flores em outubro e dezembro, e com frutos em dezembro. 